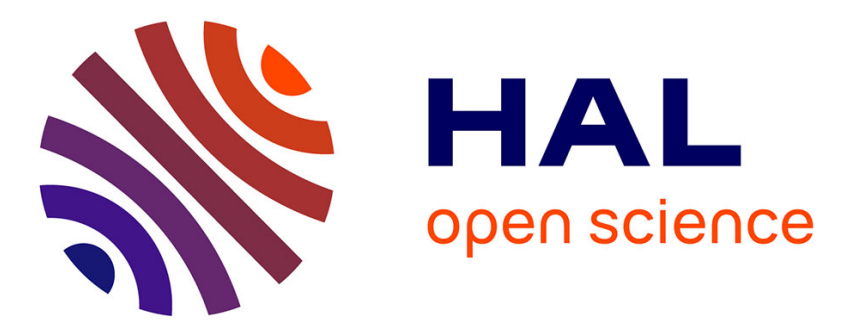

\title{
Toward an effective strategy in glioblastoma treatment. Part I: resistance mechanisms and strategies to overcome resistance of glioblastoma to temozolomide.
} Khaled Messaoudi, Anne Clavreul, Frédéric Lagarce

\section{- To cite this version:}

Khaled Messaoudi, Anne Clavreul, Frédéric Lagarce. Toward an effective strategy in glioblastoma treatment. Part I: resistance mechanisms and strategies to overcome resistance of glioblastoma to temozolomide.. Drug Discovery Today, 2015, 20 (7), pp.899-905. 10.1016/j.drudis.2015.02.011 . hal01392441

\author{
HAL Id: hal-01392441 \\ https://hal.science/hal-01392441
}

Submitted on 7 Sep 2021

HAL is a multi-disciplinary open access archive for the deposit and dissemination of scientific research documents, whether they are published or not. The documents may come from teaching and research institutions in France or abroad, or from public or private research centers.
L'archive ouverte pluridisciplinaire HAL, est destinée au dépôt et à la diffusion de documents scientifiques de niveau recherche, publiés ou non, émanant des établissements d'enseignement et de recherche français ou étrangers, des laboratoires publics ou privés. 


\title{
Toward an effective strategy in glioblastoma treatment. Part I: resistance mechanisms and strategies to overcome resistance of glioblastoma to temozolomide
}

\author{
Khaled Messaoudi ${ }^{1,2}$, Anne Clavreul ${ }^{1,2}$ and Frédéric Lagarce ${ }^{1,2,3}$ \\ ${ }^{1}$ LUNAM Université, Angers, France \\ ${ }^{2}$ Inserm U1066, Micro et Nanomedecines Biomimétiques, IBS, Angers Cedex 9, France \\ ${ }^{3}$ Service Pharmacie, CHU Angers, France
}

Glioblastoma multiforme (GBM) is a devastating disease and the most lethal of adult brain tumors. Treatment is based on surgery, radiotherapy and chemotherapy by oral temozolomide (TMZ), which is the most potent chemotherapy agent for the treatment of GBM. Despite TMZ efficiency, the prognosis of these tumors remains poor. This is because of inherent or acquired resistance of glioma tumor cells to TMZ. This resistance is caused by DNA repair enzyme activity, overexpression of epidermal growth factor receptor (EGFR), galectin-1, murine double minute 2 (Mdm2), p53 and phosphatase and tensin homolog (PTEN) mutations. Many strategies to overcome this resistance have been developed. In this review, we will describe the main mechanisms of GBM resistance to TMZ and different strategies developed to reverse the phenotype of these tumor cells. Finally, we will discuss the drawbacks and limitations of these strategies.

\section{Introduction}

Glioblastoma multiforme (GBM) is the most common and the most aggressive primary brain tumor in adults [1]. Median survival is 14.6 months [2] and the percentage of patients living for five years or more is less than $10 \%$ [3]. Despite the advances made during the past few years in brain tumor therapy, the prognosis of this disease has not improved as a result of tumor resistance. Current therapy includes surgical intervention, radiotherapy and chemotherapy with temozolomide (TMZ) [4]. TMZ is used at the beginning of GBM treatment at the daily dose of $75 \mathrm{mg} / \mathrm{m}^{2}$ body surface area in association with radiotherapy for six weeks followed by six cycles of TMZ alone at the dose of $150-200 \mathrm{mg} / \mathrm{m}^{2}$ for five days every 28 days. With this combination (TMZ plus radiotherapy), the median survival reached 14.6 months compared with 12 months for patients treated by radiotherapy alone [4]. The efficacy of TMZ for treating GBM is thus limited; this is partly because of the high levels of activity of $O^{6}$-methylguanine DNA methyltransferase (MGMT) DNA repair in tumor cells, which reduces the effect of this alkylating agent and leads to a resistant

Corresponding author. Lagarce, F. (frederic.lagarce@univ-angers.fr) phenotype. Unfortunately, other mechanisms contribute significantly to the resistance to TMZ such as overexpression of epidermal growth factor receptor (EGFR), galectin-1, murine double minute $2(\mathrm{Mdm} 2)$ and p53 gene mutation. To reduce acquired resistance, different therapeutic molecules have been developed, for example, $O^{6}$-benzyl-guanine which inhibits MGMT, tyrosine kinase inhibitors that act on EGFR, nutlin-3 which inhibits Mdm2, which contributes to the restoration of p53 activity. Despite their effectiveness, these molecules do not seem to be able to cure GBMs. However, the considerable development of RNA interference (RNAi)-based therapy seems to give hope to patients with GBMs. In this review, the main mechanisms of resistance of GBMs to TMZ and strategies that have been developed to overcome this resistance are described. Finally, we provide a critical evaluation of future prospects and challenges for treatment of GBMs.

\section{Structure and mechanism of action of temozolomide} TMZ is an alkylating agent from the imidazotetrazine family which is stable only at acidic $\mathrm{pH}$ [5]. This prodrug undergoes rapid chemical conversion in the systemic circulation at physiological $\mathrm{pH}$ to the active compound 3-methyl-(triazen-1-yl) 


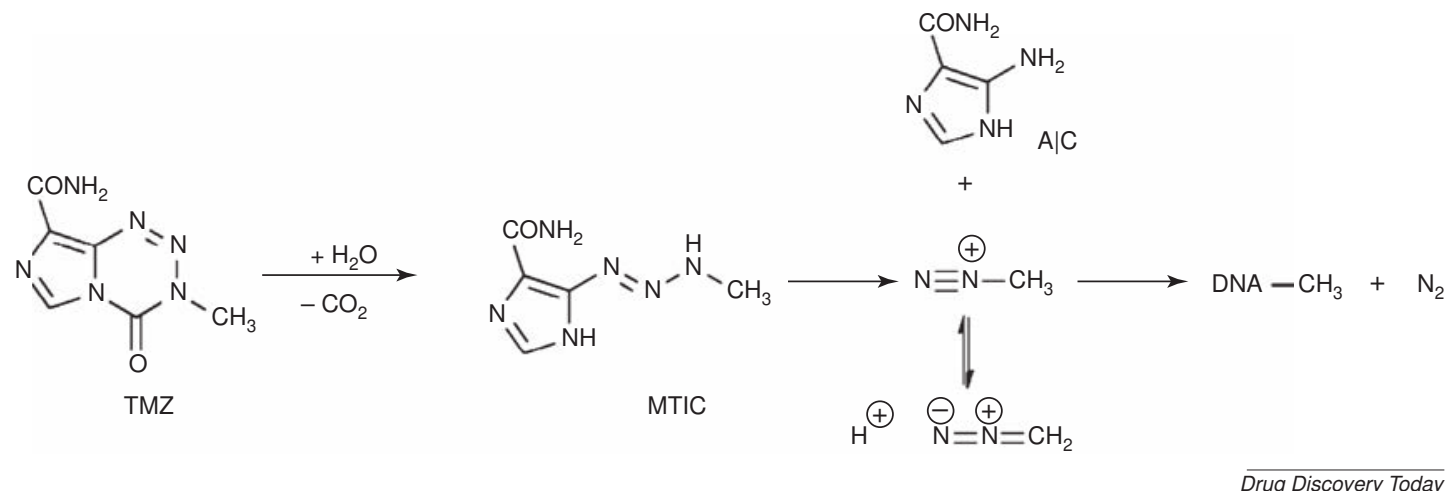

FIGURE 1

Structure and activation of temozolomide (TMZ) and production of active compound imidazole-4-carboxamide (MTIC) [5].

imidazole-4-carboxamide (MTIC), which will react with water to produce 5-aminoimidazole-4-carboxamide (AIC) and the highly reactive methyldiazonium cation (half life $=0.4 \mathrm{~s}$ ). This unstable cation transfers a methyl group to DNA causing the cytotoxic effect of TMZ [6] (Fig. 1). The methylation occurs at purine bases of DNA at the $O^{6}$ and $N^{7}$ positions of guanine and the $N^{3}$ position of adenine. The $\mathrm{O}^{6}$ methylation accounts for $5 \%$ of the total lesions caused by TMZ in DNA but it is the main cause of the TMZ cytotoxicity [7]. The $N^{7}$ and $N^{3}$ methylations are very frequent and represent $80-85 \%$ and $8-18 \%$ of total alkylations, respectively [8].

\section{Mechanisms of GBM resistance to TMZ}

Through time, GBM cells become resistant to damages caused by TMZ. This resistance is related to the implementation of several mechanisms such as DNA repair mechanisms, the overexpression of EGFR, galectin-1 and Mdm2 and the mutation of p53 and phosphatase and tensin homolog (PTEN). In addition, certain microRNA (miRNA) expression profiles are altered in GBM with overexpression of some and a significant reduction in the production of others.

\section{DNA repair mechanisms \\ MGMT}

The main mechanism of GBM resistance involves MGMT DNA enzyme repair. MGMT is a $22 \mathrm{kDa}$ protein, capable of removing not only the methyl groups attached to the $O^{6}$ position in guanines but also other alkyl groups such as ethyl, isopropyl and butyl [9]. However, MGMT removes methyl groups much faster than other alkyls [9]. It allows a direct repair of the lesion caused by TMZ by removing the methyl group in position $O^{6}$ of guanine [10] (Fig. 2). It acts as a suicide enzyme because the fixing of the methyl group on cysteine residue 145 located in its catalytic pocket causes its inactivation [11] (Fig. 2). MGMT is not recycled and undergoes degradation by the proteasome [12]. The levels of MGMT vary widely according to the type of tumor and also within the same type of tumor [13]. The MGMT gene is not commonly mutated or deleted [13]. MGMT expression is correlated to the methylation profile of the MGMT promoter. Some studies have shown that the level of MGMT is inversely related to the density of the cysteinephosphate-guanine (CpG) methylation in CpG islands [14].
MGMT gene silencing is ensured by hypermethylation of promoter CpG islands [15]. Approximately, $45 \%$ of patients with newly diagnosed GBM present a methylation of the MGMT promoter and, thus, respond better to TMZ [16]. Therapeutic molecules that inhibit MGMT such as $O^{6}$-benzyl guanine $\left(O^{6}-\mathrm{BG}\right)$ and $O^{6}$-(4bromothenyl) guanine have been used in clinical trials preceding treatment with TMZ $[8,17,18]$ (Table 1 ). These pseudosubtrates gave promising results by enhancing TMZ activity in vitro and in vivo in tumor cells possessing high levels of MGMT. They react with MGMT by covalent transfer of the benzyl group or bromothenyl group to the active cysteine residue of MGMT and cause an irreversible inactivation of this enzyme. Despite the effectiveness of the association of these pseudosubstrates with TMZ, their high toxicity against normal cells especially bone marrow cells is an obstacle to the use of these molecules [19].

\section{MMR alteration}

DNA mismatch repair (MMR) is a system that corrects errors of nucleotide base mismatches generated during DNA synthesis [8]. In the absence of MGMT, the $O^{6}$-MG persists and it can pair with thymine. The resulting $O^{6}-\mathrm{MG} / \mathrm{T}$ is recognized by MMR and only newly synthesized strands are excised, keeping $O^{6}$-MG intact. This repair cycle is repeated when another strand is generated. These futile cycles of insertion and excision of thymine occur and lead to cell cycle arrest and apoptosis $[8,20]$. An impaired MMR pathway caused by mutations in MMR protein complexes causes a failure to recognize and repair $O^{6}-\mathrm{MG}$ adducts produced by TMZ. This causes DNA replication and allows the cell cycle to continue and thereby makes TMZ less effective [21]. These mutations can be present naturally or acquired by TMZ regimens [22]. Because of its importance, strategies to restore the effect of the MMR system should be developed to improve the effect of TMZ.

\section{$\boldsymbol{B E R}$}

This system is involved in the repair of DNA damage caused by oxidizing agents, ionizing radiation or alkylating agents $[23,24]$. The base excision repair (BER) system comprises proteins and enzymes. Among them, poly(ADP-ribose) polymerase-1 (PARP-1) is an enzyme activated in response to DNA damage and plays an important part in the BER system. This enzyme binds to DNA and begins the synthesis of a poly(ADP-ribose) (PAR) from NAD+, which enables the recruitment of BER complex proteins (XRCC1, DNA polymerase, ligase, flap endonuclease 1) and the DNA repair [25]. 


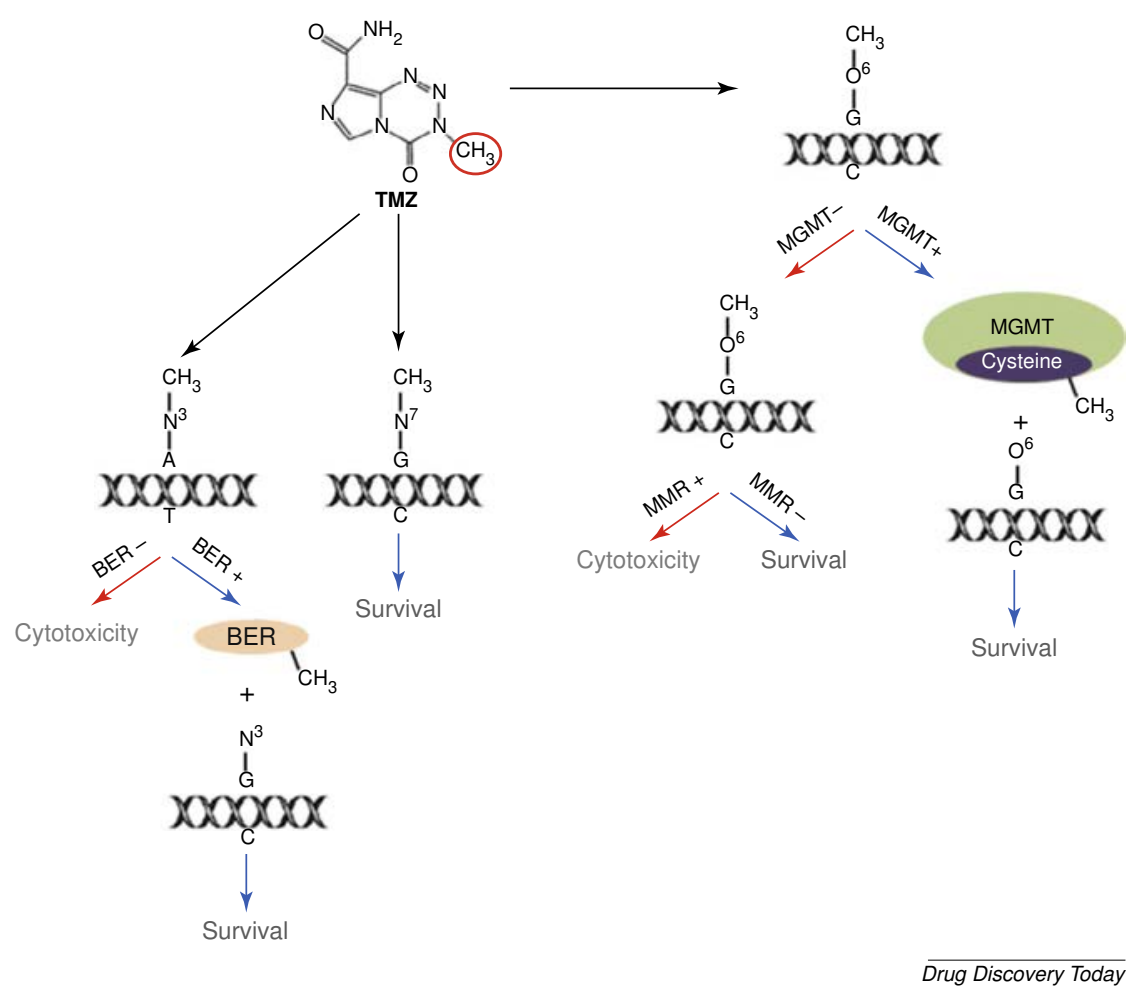

FIGURE 2

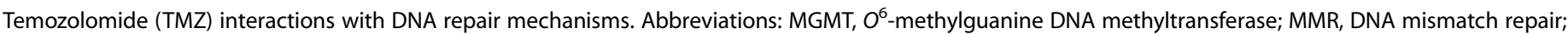
BER, base excision repair.

The BER pathway is involved in repair of $N^{3}$ and $N^{7}$ methylations caused by TMZ $[8,20,26]$. The $N^{3}$ lesions are lethal if not repaired contrary to $N^{7}$ lesions $[8,27]$. These methylations that represent more than $90 \%$ methylation caused by TMZ are rapidly repaired by BER. However, TMZ becomes toxic when one or more components of BER have mutations. Thus, the development of PARP inhibitors, limiting BER activity, seems to be a promising strategy for enhancing the effect of TMZ [28]. However, despite the high rate of methylation at $N^{7}$ and $N^{3}$ compared with $O^{6}$ methylation, the role of BER in TMZ resistance is less important than MMR or MGMT.

\section{Overexpression of EGFR and galectin-1 \\ EGFR}

EGFR (170 kDa) is one of the receptors that plays an important part in tumor development by stimulating cell proliferation, migration, angiogenesis and cell resistance to chemotherapy [29]. Ligand binding to wild-type EGFR will result in the activation of one of the following signaling pathways: Ras/Raf/MAPK (mitogenactivated kinases) [30] or PI3K/AKT/mTOR [31]. These signaling pathways are activated strongly in GBMs, causing inhibition of cell autophagy and apoptosis responsible for the decrease of TMZ efficiency [32] (Fig. 3).

EGFR gene amplification is the most frequent genetic alteration in primary GBMs with frequency of 40\% [33] and approximately half of these tumors carry the rearranged EGFR gene resulting in tumors expressing wild-type EGFR as well as a mutated EGFR [34]. EGFR variant III (EGFRvIII) is the most common variant of EGFR in GBMs, it is characterized by a deletion of 267 amino acids in the extracellular domain, which leads to the formation of a receptor unable to bind a ligand and which has a constitutive tyrosine kinase activity.

Therapeutic molecules have been developed to inhibit the EGFR signaling pathway. For example, Cetuximab ${ }^{\circledR}$, a monoclonal antibody binding specifically to EGFR, inhibits downstream signal transduction pathways [35] (Table 1). Cetuximab ${ }^{\circledR}$ is able to recognize the wild-type EGFR and EGFRvIII leading to an inhibition of cell proliferation in vitro. However, its use in the clinic gave disappointing results with a median survival of five months [36]. Currently, a Phase I/II clinical trial is ongoing to study the efficacy of combining radiotherapy, TMZ and Cetuximab ${ }^{\mathbb{B}}$ for treatment of patients with primary GBM [37]. Gefitinib ${ }^{\circledR}$ and Erlotinib ${ }^{\circledR}$ which are tyrosine kinase inhibitors (TKIs) are other therapeutic molecules used to inhibit EGFR signaling pathways (Table 1). They act by binding to the cytoplasmic ATP pocket domain blocking EGFR phosphorylations and, thereby, EGFR-mediated activation of downstream pathways [38]. These molecules have been tested in clinical trials (Phase I and II) in patients with GBM $[39,40]$. Unfortunately, disappointing results were obtained. Indeed, the use of Gefitinib ${ }^{\mathbb{R}}$ or Erlotinib ${ }^{\mathbb{R}}$ in association to radiotherapy has shown a modest improvement in patient survival $[41,42]$. The associations of TKIs and TMZ have been evaluated and showed an improvement of median survival compared with TMZ associated to radiotherapy but only a small subpopulation experienced sustainable disease control. Indeed, the response of GBM patients was correlated with the presence of intact PTEN [36]. In addition, patients with MGMT promoter methylation and intact PTEN had a significant survival advantage [40]. 
TABLE 1

Different strategies tested in vitro and in preclinical and clinical trials for inhibition of molecules involved in TMZ resistance in GBM

\begin{tabular}{|c|c|c|c|c|c|}
\hline Molecule & Target & Mechanism of action & Effect & Limitations to use in clinic & Refs \\
\hline $\begin{array}{l}O^{6} \text {-Benzyl guanine }\left(O^{6}-\mathrm{BG}\right) \\
\text { and } O^{6} \text {-(4-bromothenyl) } \\
\text { guanine }\end{array}$ & MGMT & $\begin{array}{l}\text { Irreversible inactivation of } \\
\text { MGMT by covalent link of } \\
\text { benzyl or bromothenyl groups } \\
\text { to the active cysteine residue } \\
\text { of MGMT }\end{array}$ & $\begin{array}{l}\text { Enhancing TMZ activity in } \\
\text { vitro and in animal models } \\
\text { on tumor cells possessing } \\
\text { high levels of MGMT }\end{array}$ & $\begin{array}{l}\text { High toxicity against normal } \\
\text { cells especially bone marrow } \\
\text { cells }\end{array}$ & {$[8,17-19]$} \\
\hline Cetuximab $^{\circledR}$ & EGFR & $\begin{array}{l}\text { Monoclonal antibody binding } \\
\text { specifically to EGFR }\end{array}$ & $\begin{array}{l}\text { Specific recognition of the } \\
\text { wild-type EGFR and } \\
\text { EGFRvIll in vitro which } \\
\text { causes an inhibition of cell } \\
\text { proliferation }\end{array}$ & $\begin{array}{l}\text { Disappointing results in the } \\
\text { clinic }\end{array}$ & [36] \\
\hline Gefitinib $^{\circledR}$ and Erlotinib ${ }^{\circledR}$ & & TKls & $\begin{array}{l}\text { Association of TKIs and } \\
\text { TMZ showed an } \\
\text { improvement of survival } \\
\text { median compared with the } \\
\text { combination } \\
\text { TMZ + radiotherapy }\end{array}$ & $\begin{array}{l}\text { In clinical trials: effective only } \\
\text { in subpopulation of patients } \\
\text { with intact PTEN and MGMT } \\
\text { promoter methylation }\end{array}$ & {$[36,40]$} \\
\hline Nutlin-3 & Mdm2 & $\begin{array}{l}\text { Binding to Mdm2 and } \\
\text { activation of the p53 pathway }\end{array}$ & $\begin{array}{l}\text { Activation of the p53 } \\
\text { pathway in cancer cells, } \\
\text { leading to cell cycle arrest, } \\
\text { apoptosis and growth } \\
\text { inhibition of human tumor } \\
\text { xenografts in nude mice }\end{array}$ & $\begin{array}{l}\text { Effective only in cancer cells } \\
\text { expressing wild-type p53 } \\
\text { Potential toxic effect by p53 } \\
\text { accumulation }\end{array}$ & {$[61,64,65]$} \\
\hline Synthetic lactulose amines & Galectin-1 & $\begin{array}{l}\beta \text {-Galactoside which has an } \\
\text { affinity for the CRD of } \\
\text { Galectin-1 }\end{array}$ & $\begin{array}{l}\text { Tumor cell apoptosis and } \\
\text { suppression of tumor } \\
\text { growth and metastasis }\end{array}$ & $\begin{array}{l}\text { Potential gastrointestinal side- } \\
\text { effects }\end{array}$ & {$[53,54,80]$} \\
\hline Galactomannan Davanat $^{\circledR}$ & & $\begin{array}{l}\text { Binds Galectin-1 at a site } \\
\text { distinct from the CRD }\end{array}$ & $\begin{array}{l}\text { Davanat }{ }^{\circledR} \text { increased the } \\
\text { longevity of patients with } \\
\text { colorectal cancer by } 46 \% \\
\text { compared with the best } \\
\text { standard of care, and } \\
\text { reduced the serious } \\
\text { adverse effects by } 41 \% \\
\text { compared with the best } \\
\text { standard of care }\end{array}$ & $\begin{array}{l}\text { Not yet tested in GBM in } \\
\text { clinical trials }\end{array}$ & \\
\hline
\end{tabular}

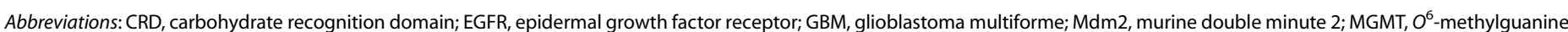
DNA methyltransferase; PTEN, phosphatase and tensin homolog; TKls, tyrosine kinase inhibitors; TMZ, temozolomide.

\section{Galectin-1}

This protein belongs to the lectin family containing a carbohydrate recognition domain (CRD) with a high affinity for $\beta$-galactosides $[2,43]$. Galectin-1 is present inside and outside cells, and has intracellular and extracellular functions. The intracellular activity of galectin-1 is dependent on protein-protein interaction, whereas its extracellular activity is dependent on its lectin activity [44]. In astrocytomas there is a relationship between the expression level of galectin-1 and the grade of malignancy [45].

Galectin-1 is a hypoxia-regulated protein; its production and secretion are stimulated by hypoxia [46]. Galectin-1 has been shown to have important functions in several aspects of cancer biology implicating cell migration by interaction with integrins and components of the extracellular matrix [47], metastasis formation [48], stimulation of angiogenesis by regulating the ORP150 that controls the maturation and secretion of vascular endothelial growth factor (VEGF) [49], chemo- and radio-resistance by interaction with Ras protein $[50,51]$ and modulation of p53 migration in the nucleus [50] (Fig. 3). In addition, galectin-1 inhibits T cell effector function by promoting apoptosis, allowing tumors to evade the immune system $[46,52]$. In view of its important role in the chemo- and radio-resistance, targeting galectin- 1 by different strategies was considered. Among them, the use of synthetic lactulose as $\beta$-galactoside, which has an affinity for the CRD of galectin-1 [53] (Table 1), and the use of galactomannan (Davanat $\left.{ }^{\circledR}\right)$, which binds to galectin-1 at a site distinct from the CRD [54] (Table 1). Davanat ${ }^{\circledR}$ was approved by the FDA for treatment of colorectal cancers and gave promising results. However, more investigations must be done for evaluation of its effect on GBM.

\section{p53, Mdm2 and PTEN}

\section{p53 and Mdm2}

In humans, p53 is a tumor suppressor protein encoded by the TP53 gene that can induce a temporary or permanent cessation of cell growth in response to cellular stress such as DNA damage $[55,56]$. Certain frequent TP53 mutations lead to the loss of function of tumor suppressor p53 and a p53 mutant protein accumulation. Unlike wild-type p53, which under normal conditions has a short half-life owing to the inhibitory action of Mdm2 [56], the mutated p53 does not undergo this inhibition and accumulates to high levels in cancer cells [57]. Mdm2 is a frequently amplified gene in GBM [58]. Its overexpression causes a loss of function of p53, in 


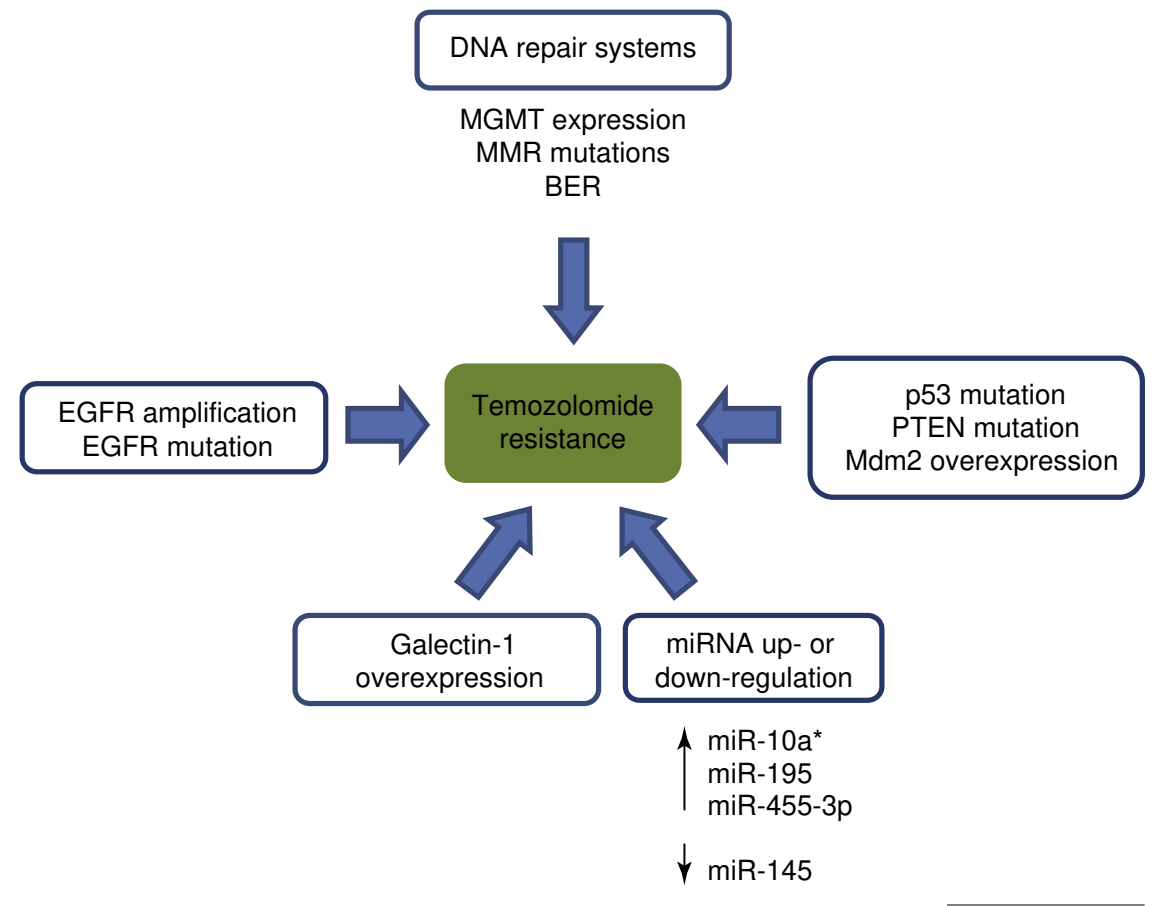

$\overline{\text { Drug Discovery Today }}$

FIGURE 3

Different actors involved in the resistance of glioma tumor cells to TMZ.

addition to mutation of the TP53 gene [59] leading to the promotion of tumor cell growth and a resistance to chemoradiotherapy [60] (Fig. 3).

Because of the crucial role of p53 deficiency in glioma development and resistance to anticancer drugs, many strategies were developed to restore the effect of p53. Gene therapy to restore p53 function and inhibitors of p53-Mdm2 interaction are the most important [61]. Indeed, gene therapy provides the direct delivery of wild-type p53 in cancer cells. The adenoviral delivery of p53 was tested and has shown that it can improve the quality of life and the prognosis in patients with recurrent malignant gliomas [62]. Targeting the interaction of Mdm2 with p53 is also a potential cancer therapeutic strategy because of $\mathrm{Mdm} 2$ overexpression in gliomas [63]. The treatment of cells with an inhibitor of p53-Mdm2 binding should result in stabilization and accumulation of the wild-type p53 protein [64]. Nutlin-3 is one of the molecules that has been developed for this purpose and has yielded interesting results in preclinical studies. Its action is related to its binding to Mdm2 in the p53 binding pocket, activating the p53 pathway $[61,64]$ (Table 1$)$. The main limitation of inhibitors of p53-Mdm2 interaction is that they are effective only in cancer cells expressing wild-type p53, and have no effect in cells expressing mutant p53. Moreover, it is important to consider the toxic effect that can cause overexpression of p53 on normal cells expressing wild-type p53 [65].

\section{PTEN}

PTEN is a tumor suppressor enzyme, frequently mutated in GBM leading to an enhancement of tumor cell proliferation $[66,67]$. PTEN protects wild-type p53 from inactivation and degradation through the inhibition of PI3K and inhibition of Mdm2 transcription [68]. By contrast, p53 is able to increase the PTEN activity by enhancing PTEN gene transcription by binding to the PTEN promoter [69], p53 can be stabilized by binding with PTEN which can also enhance the transcriptional activity of the TP53 gene [70]. Restoration of wild-type PTEN into tumors in which it is absent or mutated suppresses tumorigenicity, promotes apoptosis and can induce chemosensitivity $[68,71]$. This indicates that the association of wild-type PTEN and wild-type p53 can enhance the sensitivity of tumor cells to anticancer drugs especially to TMZ (Fig. 3).

\section{miRNAs}

miRNAs have a crucial role as a novel class of oncogenes or tumor suppressor genes [72]. Some studies have shown that aberrant miRNA expression could affect GBM sensitivity to TMZ [73]. For example, miR-21, miR-195, miR-455-3p and miR-10a* are upregulated in a TMZ-resistant cell line $[74,75]$. By contrast, miR-145 is downregulated in GBM tumor cells, this enhances TMZ resistance [76] (Fig. 3). miRNAs can be exploited for the development of a new therapeutic strategy. Indeed, the oncogenic miRNAs can be downregulated using antisense oligonucleotides or miRNA sponges [77,78], whereas tumor-suppressive miRNAs can be replaced with miRNA mimetics [79].

\section{Concluding remarks}

The development of molecular biology has identified the targets involved in the resistance of GBMs to TMZ and helped in understanding their mode of cross involvement. This accelerated the development of new strategies to inhibit the effect of these targets and potentially increase the effectiveness of TMZ. However, despite promising results in vitro and in vivo, these strategies have shown their limits in terms of efficacy and side-effects in the clinic. Indeed, the systemically administered treatments lack selectivity 
because they will be distributed in the target tissue and healthy tissue causing side-effects of varying severity. It also appears that inhibiting a target is not sufficient to reverse resistance to TMZ; in fact there are so many pathways in tumor cell biology that compensation mechanisms often occur. Moreover, the targets are located in the brain and thus the drugs must cross the bloodbrain barrier, which is difficult to achieve. For these reasons these

\section{References}

1 Stupp, R. et al. (2005) Radiotherapy plus concomitant and adjuvant temozolomide for glioblastoma. N. Engl. J. Med. 352, 987-996

2 Lefranc, F. et al. (2006) Present and potential future issues in glioblastoma treatment. Expert Rev. Anticancer Ther. 6, 719-732

3 Lefranc, F. et al. (2007) Proautophagic drugs: a novel means to combat apoptosisresistant cancers, with a special emphasis on glioblastomas. Oncologist 12, 1395-1403

4 Stupp, R. et al. (2009) Effects of radiotherapy with concomitant and adjuvant temozolomide versus radiotherapy alone on survival in glioblastoma in a randomised Phase III study: 5-year analysis of the EORTC-NCIC trial. Lancet Oncol. 10, 459-466

5 Pletsas, D. et al. (2013) Synthesis and quantitative structure-activity relationship of imidazotetrazine prodrugs with activity independent of $O^{6}$-methylguanine-DNAmethyltransferase, DNA mismatch repair, and p53. J. Med. Chem. 56, 7120-7132

6 Friedman, H.S. et al. (2000) Temozolomide and treatment of malignant glioma. Clin. Cancer Res. 6, 2585-2597

7 Drablos, F. et al. (2004) Alkylation damage in DNA and RNA-repair mechanisms and medical significance. DNA Repair 3, 1389-1407

8 Zhang, J. et al. (2012) Temozolomide: mechanisms of action, repair and resistance. Curr. Mol. Pharmacol. 5, 102-114

9 Kaina, B. et al. (2007) MGMT: key node in the battle against genotoxicity, carcinogenicity and apoptosis induced by alkylating agents. DNA Repair 6, 1079-1099

10 Park, C.K. et al. (2012) The changes in MGMT promoter methylation status in initial and recurrent glioblastomas. Transl. Oncol. 5, 393-397

11 Tubbs, J.L. et al. (2007) DNA binding, nucleotide flipping, and the helix-turn-helix motif in base repair by $O^{6}$-alkylguanine-DNA alkyltransferase and its implications for cancer chemotherapy. DNA Repair 6, 1100-1115

12 Xu-Welliver, M. and Pegg, A.E. (2002) Degradation of the alkylated form of the DNA repair protein, O(6)-alkylguanine-DNA alkyltransferase. Carcinogenesis 23, 823-830

13 Esteller, M. et al. (2000) Inactivation of the DNA-repair gene MGMT and the clinical response of gliomas to alkylating agents. N. Engl. J. Med. 343, 1350-1354

14 Bhakat, K.K. and Mitra, S. (2003) CpG methylation-dependent repression of the human $O^{6}$-methylguanine-DNA methyltransferase gene linked to chromatin structure alteration. Carcinogenesis 24, 1337-1345

15 Silber, J.R. et al. (2012) O(6)-methylguanine-DNA methyltransferase in glioma therapy: promise and problems. Biochim. Biophys. Acta 1826, 71-82

16 Hegi, M.E. et al. (2005) MGMT gene silencing and benefit from temozolomide in glioblastoma. N. Engl. J. Med. 352, 997-1003

17 Kaina, B. et al. (2010) Targeting O(6)-methylguanine-DNA methyltransferase with specific inhibitors as a strategy in cancer therapy. Cell Mol. Life Sci. 67, 3663-3681

18 Verbeek, B. et al. (2008) $O^{6}$-Methylguanine-DNA methyltransferase inactivation and chemotherapy. Br. Med. Bull. 85, 17-33

19 Hansen, W.K. and Kelley, M.R. (2000) Review of mammalian DNA repair and translational implications. J. Pharmacol. Exp. Ther. 295, 1-9

$20 \mathrm{Fu}$, D. et al. (2012) Balancing repair and tolerance of DNA damage caused by alkylating agents. Nat. Rev. Cancer 12, 104-120

21 Liu, L. et al. (1996) Mismatch repair mutations override alkyltransferase in conferring resistance to temozolomide but not to 1,3-bis(2-chloroethyl)nitrosourea Cancer Res. 56, 5375-5379

22 Yip, S. et al. (2009) MSH6 mutations arise in glioblastomas during temozolomide therapy and mediate temozolomide resistance. Clin. Cancer Res. 15, 4622-4629

23 Almeida, K.H. and Sobol, R.W. (2007) A unified view of base excision repair: lesiondependent protein complexes regulated by post-translational modification. DNA Repair 6, 695-711

24 Wood, R.D. et al. (2001) Human DNA repair genes. Science 291, 1284-1289

25 Malanga, M. and Althaus, F.R. (2005) The role of poly(ADP-ribose) in the DNA damage signaling network. Biochem. Cell Biol. 83, 354-364

26 Denny, B.J. et al. (1994) NMR and molecular modeling investigation of the mechanism of activation of the antitumor drug temozolomide and its interaction with DNA. Biochemistry 33, 9045-9051 tumors remain incurable at present and new effective strategies to deliver innovative drugs at their targets are strongly needed. This issue will be addressed in the second review in this series.

\section{Acknowledgment}

The authors a very grateful to the Ligue contre le Cancer, Comite du Maine et Loire, France that funded this work.
27 Horton, J.K. and Wilson, S.H. (2007) Hypersensitivity phenotypes associated with genetic and synthetic inhibitor-induced base excision repair deficiency. DNA Repair $6,530-543$

28 Munoz-Gamez, J.A. et al. (2014) Synergistic cytotoxicity of the poly (ADP-ribose) polymerase inhibitor ABT-888 and temozolomide in dual-drug targeted magnetic nanoparticles. Liver Int. http://dx.doi.org/10.1111/liv.12586

29 Huang, P.H. et al. (2009) Oncogenic EGFR signaling networks in glioma. Sci. Signal. 2 , re6

30 Guha, A. et al. (1997) Proliferation of human malignant astrocytomas is dependent on Ras activation. Oncogene 15, 2755-2765

31 Narita, Y. et al. (2002) Mutant epidermal growth factor receptor signaling downregulates $\mathrm{p} 27$ through activation of the phosphatidylinositol 3-kinase/Akt pathway in glioblastomas. Cancer Res. 62, 6764-6769

32 Furuta, S. et al. (2004) Ras is involved in the negative control of autophagy through the class I PI3-kinase. Oncogene 23, 3898-3904

33 Ekstrand, A.J. et al. (1991) Genes for epidermal growth factor receptor, transforming growth factor alpha, and epidermal growth factor and their expression in human gliomas in vivo. Cancer Res. 51, 2164-2172

34 Lo, H.W. (2010) EGFR-targeted therapy in malignant glioma: novel aspects and mechanisms of drug resistance. Curr. Mol. Pharmacol. 3, 37-52

35 Weiner, L.M. et al. (2010) Monoclonal antibodies: versatile platforms for cancer immunotherapy. Nat. Rev. Immunol. 10, 317-327

36 Neyns, B. et al. (2009) Stratified Phase II trial of cetuximab in patients with recurrent high-grade glioma. Ann. Oncol. 20, 1596-1603

37 Combs, S.E. et al. (2006) Treatment of primary glioblastoma multiforme with cetuximab, radiotherapy and temozolomide (GERT) - Phase I/II trial: study protocol. BMC Cancer 6, 133

38 Brandes, A.A. et al. (2008) Epidermal growth factor receptor inhibitors in neurooncology: hopes and disappointments. Clin. Cancer Res. 14, 957-960

39 Brown, P.D. et al. (2008) Phase I/II trial of erlotinib and temozolomide with radiation therapy in the treatment of newly diagnosed glioblastoma multiforme: North Central Cancer Treatment Group Study N0177. J. Clin. Oncol. 26, 56035609

40 Prados, M.D. et al. (2009) Phase II study of erlotinib plus temozolomide during and after radiation therapy in patients with newly diagnosed glioblastoma multiforme or gliosarcoma. J. Clin. Oncol. 27, 579-584

41 Chakravarti, A. et al. (2013) RTOG 0211: a Phase 1/2 study of radiation therapy with concurrent gefitinib for newly diagnosed glioblastoma patients. Int. J. Radiat. Oncol Biol. Phys. 85, 1206-1211

42 Uhm, J.H. et al. (2011) Phase II evaluation of gefitinib in patients with newly diagnosed grade 4 astrocytoma: Mayo/North Central Cancer Treatment Group Study N0074. Int. J. Radiat. Oncol. Biol. Phys. 80, 347-353

43 Liu, F.T. and Rabinovich, G.A. (2005) Galectins as modulators of tumour progression. Nat. Rev. Cancer 5, 29-41

44 Camby, I. et al. (2006) Galectin-1: a small protein with major functions. Glycobiology $16,137-157 \mathrm{R}$

45 Verschuere, T. et al. (2011) Galectin-1 and immunotherapy for brain cancer. Expert Rev. Neurother. 11, 533-543

46 Le, Q.T. et al. (2005) Galectin-1: a link between tumor hypoxia and tumor immune privilege. J. Clin. Oncol. 23, 8932-8941

47 Camby, I. et al. (2005) Galectin-1 knocking down in human U87 glioblastoma cells alters their gene expression pattern. Biochem. Biophys. Res. Commun. 335, 27-35

48 Rabinovich, G.A. et al. (2002) Galectins and their ligands: amplifiers, silencers or tuners of the inflammatory response? Trends Immunol. 23, 313-320

49 Le Mercier, M. et al. (2010) Galectins and gliomas. Brain Pathol. 20, 17-27

50 Le Mercier, M. et al. (2008) Evidence of galectin-1 involvement in glioma chemoresistance. Toxicol. Appl. Pharmacol. 229, 172-183

51 Paz, A. et al. (2001) Galectin-1 binds oncogenic H-Ras to mediate Ras membrane anchorage and cell transformation. Oncogene 20, 7486-7493 
52 Rubinstein, N. et al. (2004) Targeted inhibition of galectin-1 gene expression in tumor cells results in heightened $\mathrm{T}$ cell-mediated rejection: a potential mechanism of tumor-immune privilege. Cancer Cell 5, 241-251

53 Rabinovich, G.A. et al. (2006) Synthetic lactulose amines: novel class of anticance agents that induce tumor-cell apoptosis and inhibit galectin-mediated homotypic cell aggregation and endothelial cell morphogenesis. Glycobiology 16, 210-220

54 Miller, M.C. et al. (2009) The alpha-galactomannan Davanat binds galectin-1 at a site different from the conventional galectin carbohydrate binding domain. Glycobiology 19, 1034-1045

55 Fridman, J.S. and Lowe, S.W. (2003) Control of apoptosis by p53. Oncogene 22, 9030 9040

56 Shangary, S. and Wang, S. (2009) Small-molecule inhibitors of the MDM2-p53 protein-protein interaction to reactivate p53 function: a novel approach for cancer therapy. Annu. Rev. Pharmacol. Toxicol. 49, 223-241

57 Petitjean, A. et al. (2007) TP53 mutations in human cancers: functional selection and impact on cancer prognosis and outcomes. Oncogene 26, 2157-2165

58 Freedman, D.A. et al. (1999) Functions of the MDM2 oncoprotein. Cell. Mol. Life Sci. 55, 96-107

59 Burton, E.C. et al. (2002) Aberrant p53, mdm2, and proliferation differ in glioblastomas from long-term compared with typical survivors. Clin. Cancer Res. 8 , 180-187

60 Shchors, K. et al. (2013) Using a preclinical mouse model of high-grade astrocytoma to optimize p53 restoration therapy. Proc. Natl. Acad. Sci. U. S. A. 110, E1480-E1489

61 Hong, B. et al. (2014) Targeting tumor suppressor p53 for cancer therapy: strategies, challenges and opportunities. Curr. Drug Targets 15, 80-89

62 Zhu, J.X. et al. (2010) Treatment of recurrent malignant gliomas by surgery combined with recombinant adenovirus-p53 injection. Zhonghua Zhong Liu Za Zhi 32, 709-712

63 Wang, A.L. et al. (2011) Expression and significance of p53 protein and MDM-2 protein in human gliomas. Chin. Med. J. 124, 2530-2533

64 Vassilev, L.T. et al. (2004) In vivo activation of the p53 pathway by small-molecule antagonists of MDM2. Science 303, 844-848

65 Ringshausen, I. et al. (2006) Mdm2 is critically and continuously required to suppress lethal p53 activity in vivo. Cancer Cell 10, 501-514
66 Kato, H. et al. (2000) Functional evaluation of p53 and PTEN gene mutations in gliomas. Clin. Cancer Res. 6, 3937-3943

67 Knobbe, C.B. et al. (2002) PTEN signaling in gliomas. Neuro-Oncology 4, 196-211

68 Mayo, L.D. et al. (2002) PTEN protects p53 from Mdm2 and sensitizes cancer cells to chemotherapy. J. Biol. Chem. 277, 5484-5489

69 Stambolic, V. et al. (2001) Regulation of PTEN transcription by p53. Mol. Cell 8, 317 325

70 Freeman, D.J. et al. (2003) PTEN tumor suppressor regulates p53 protein levels and activity through phosphatase-dependent and -independent mechanisms. Cancer Cell 3, 117-130

71 Tanaka, M. et al. (2000) MMAC1/PTEN inhibits cell growth and induces chemosensitivity to doxorubicin in human bladder cancer cells. Oncogene 19, 5406-5412

72 Babashah, S. and Soleimani, M. (2011) The oncogenic and tumour suppressive roles of microRNAs in cancer and apoptosis. Eur. J. Cancer 47, 1127-1137

73 Mizoguchi, M. et al. (2013) Clinical implications of microRNAs in human glioblastoma. Front. Oncol. 3, 19

74 Shi, L. et al. (2010) MiR-21 protected human glioblastoma U87MG cells from chemotherapeutic drug temozolomide induced apoptosis by decreasing Bax/Bcl-2 ratio and caspase-3 activity. Brain Res. 1352, 255-264

75 Ujifuku, K. et al. (2010) miR-195, miR-455-3p and miR-10a $\left(^{*}\right)$ are implicated in acquired temozolomide resistance in glioblastoma multiforme cells. Cancer Lett. 296, 241-248

76 Yang, Y.P. et al. (2012) Inhibition of cancer stem cell-like properties and reduced chemoradioresistance of glioblastoma using microRNA145 with cationic polyurethane-short branch PEI. Biomaterials 33, 1462-1476

77 Ebert, M.S. et al. (2007) MicroRNA sponges: competitive inhibitors of small RNAs in mammalian cells. Nat. Methods 4, 721-726

78 Esau, C.C. (2008) Inhibition of microRNA with antisense oligonucleotides. Methods $44,55-60$

79 Pang, J.C. et al. (2009) Oncogenic role of microRNAs in brain tumors. Acta Neuropathol. 117, 599-611

80 Klyosov, A.A. et al. (2012) DAVANAT ${ }^{\mathbb{R}}$ (GM-CT-01) and colon cancer: preclinical and clinical (Phase I and II) studies. In Glycobiology and Drug Design, (Vol. 1102) (Klyosov, A.A., ed.), pp. 89-130, American Chemical Society 